\title{
Perspectivas na consolidação do sistema de ensino brasileiro: o desenho da democratização proposto nas leis de diretrizes e bases - Leis 4.024/61 e 9.394/96
}

\author{
Consolidation perspectives of Brazilian educational \\ system: the democratization design proposed in \\ educational laws - 4.024/61 and 9.394/96
}

\author{
Oséias Santos de Oliveira1 \\ Clarice Zientarski² \\ Neila Pedrotti Drabach ${ }^{3}$ \\ Sueli Menezes Pereira ${ }^{4}$
}

\section{Resumo}

Este trabalho investiga as políticas de organização dos sistemas de ensino brasileiro no contexto da LDB 4.024/61 e da LDB 9.394/96 e as interferências sofridas no percurso de discussão e implementação das mesmas, em especial na atual perspectiva de descentralização proposta pela Constituição Federal de 1988 elaborada no contexto de confluências entre projetos sociais democráticos e interesses neoliberais. Busca-se uma revisão contextual dos antecedentes históricos que delimitam 0 surgimento dessas legislações educacionais, bem como os reflexos dos condicionantes políticos e econômicos no processo de redemocratização da educação nacional. Tendo como base empírica a legislação educacional do período de 1930 aos dias atuais, a abordagem crítico-dialética possibilita um olhar retrospectivo e reflexivo sobre as políticas que delimitam a redução do papel do Estado no atendimento das demandas sociais, dentre elas a educação. Os aportes teóricos possibilitam uma análise das intenções e ações de uma sociedade que se liberta das amarras antidemocráticas e que, ao mesmo tempo, sofre os impasses dos interesses do capitalismo, com forte interferência nas normativas educacionais expostas na necessidade de implementação dos Sistemas de Ensino e a aposta na descentralização com forte apelo ao envolvimento local.

Palavras-chave: Sistema educacional; Legislação educacional; Descentralização; Democratização.

\begin{abstract}
This paper investigates the political organization of educational systems in the Brazil in 4024/61 and 9394/96 laws and the interference suffered in the course of discussion and implementation of these, especially in the current context of decentralization proposed by the Federal Constitution of 1988 developed in a context of convergence between social democratic projects and neoliberal interests. The work searches a contextual review of historical that defines the appearance of these educational laws, and the reflections of political and economic conditions in the redemocratization of national education. Based on empirical educational legislation of the period from 1930 to today, with a critical-dialectical approach, and provides a reflective look back on the policies the boundaries to reduce the State's role in meeting the social demands, among them education. The theoretical contributions provide an analysis of intentions and actions of society that releases a antidemocratic history, and at the same time have the impasses of the interests of capitalism, strong interference with the educational standards exposed the need for implementation of education system on decentralization with strong appeal for local involvement.
\end{abstract}

Keywords: Educational system; Education laws; Decentralization; Democratization.

1 Doutorando pelo Programa de Pós-Graduação em Educação//UFSM - oseias.ol@uol.com.br 2 Doutoranda pelo Programa de Pós-Graduação em Educação//UFSM - claricezientarski@yahoo.com.br 3 Mestre em Educação - Pedagoga do IFPR - neila.drabach @ifpr.edu.br 4 Doutora em Educação, Professora do Programa de Pós-Graduação em Educação/UFSM - sueli@ce.ufsm.br 
Este texto tem como proposta abordar as questões da educação nas políticas de Estado em diferentes contextos históricos, tendo como base o processo de configuração dos sistemas de ensino na legislação educacional. Tal proposta se justifica considerando a realidade atual posta pela Constituição Federal de 1988, pela qual se impõe a reforma do Estado, especialmente na década de 1990, com implicações diretas na organização da educação: gestão democrática, autonomia dos sistemas e das instituições. Tais mudanças, decorrentes do processo de descentralização das funções do Estado, proporcionalmente, acabam por repassar um maior compromisso à sociedade e em especial à comunidade escolar.

Assim, os Sistemas de Ensino, nas esferas federal, distrital, estaduais e municipais são constituídos na perspectiva de tornar possíveis as ações, intenções e planejamentos da educação brasileira propostas na Constituição Federal, na LDB 9.394/96, nos Planos de Educação e nas propostas governamentais recentes.

Os anos de 1990 foram decisivos para a definição dos rumos da educação brasileira. Decorridos trinta e cinco anos de promulgação da LDB 4.024, de 20/12/1961, foi aprovada no Congresso Nacional a Nova Lei de Diretrizes e Base da Educação Nacional - Lei no 9.394 de 20/12/1996. Esta lei é fruto de discussões, análises, lutas de interesses e de engajamento de setores da sociedade que, num anseio de participação, após décadas de impossibilidade de exercer esta prática, por cerceamento da liberdade de manifestação decorrente dos mecanismos ditatoriais instaurados no Brasil nos anos 1960 - 1980, experimentam uma prática democrática.

Para se estabelecer um paralelo e buscar compreender as atuais políticas para a área da educação torna-se necessária uma retrospectiva sobre os processos educacionais anteriores, apresentados na primeira LDB, Lei 4.024/61, e nos seus antecedentes históricos. O contexto dessa primeira Lei de Diretrizes e Bases da Educação Nacional começa a se desenhar ainda nas décadas de 1930 e 1940 quando se verifica a atuação do Estado mais com o intuito de atender às pressões do momento, com definições de políticas econômicas e de desenvolvimento. Nesse cenário, a questão educacional passa por um processo de organização, pois o sentimento nacionalista que pairava na sociedade e orientava as ações do governo precisava se firmar e, nesse contexto, a educação tem um papel relevante.

Diante dos problemas que emergem dessas situações controversas, justifica-se a necessidade de uma abordagem crítico-dialética para compreender os fatos sociais e econômicos, pela possibilidade que esta abordagem oportuniza ao questionamento da realidade social, a partir de uma postura investigativa que objetiva desvendar, mais que o "conflito das interpretações", o "conflito de interesses" (GAMBOA, 1991, p. 9798), justamente porque delimita um "interesse transformador" das situações ou fenômenos estudados, resgatando sua dimensão histórica e desvelando suas possibilidades de mudança. Tendo em vista essa dimensão investigativa, calca-se a análise no conteúdo das Leis de Diretrizes e Bases da Educação Brasileira, considerando seus respectivos momentos históricos - nacionalista liberal a partir de 1930 e globalização neoliberal a partir de 1980.

Ao buscar o clareamento desses aspectos importantes das políticas educacionais, as reflexões também caminham no sentido de compreender o papel da escola e o seu significado no esboço e na confirmação da atual sociedade inserida no contexto neoliberal.

\section{O contexto da LDB 4.024/61: interesses ou necessidades na perspectiva de uma educação nacional?}

A implantação do capitalismo industrial no Brasil, a partir de 1930, determinou uma nova organização das relações sociais, econômicas, políticas e estruturais, como a ampliação do papel do Estado e, posteriormente, do capital nacional, de modo a estabelecer um desenvolvimento econômico, social e político aos moldes dos países desenvolvidos, porém com independência em relação ao capital internacional. Dessa maneira, surgem novas exigências educacionais e novos comprometimentos que vão delimitar as políticas para a educação brasileira. 
Saviani (1998, p. 9) pontua que "a origem da temática relativa às diretrizes e bases da educação nacional remonta à Constituição Federal de 1934, a primeira das nossas cartas magnas que fixou como competência privada da União 'traçar diretrizes da educação nacional' (Artigo 5, Inciso XIV)". Essa constatação referenda a necessidade de se pensar um projeto educacional em âmbito nacional.

As profundas transformações decorrentes das relações de produção e a concentração cada vez mais ampla de população em centros urbanos tornaram fundamentais novos anseios pela qualificação para o trabalho, do mesmo modo que a oferta de instrução básica à população, pela necessidade do consumo que essa produção requer. Portanto, em decorrência das exigências do novo modo de produção e de consumo, observam-se modificações profundas na forma de conceber a educação, tendo o Estado como o principal fomentador das políticas educacionais.

No entanto, essas reformas, sob influências de caráter político-ideológico, assumiram, no campo educacional, características contraditórias, uma vez que o "sistema" de ensino passou a sofrer, de um lado, a pressão popular para sua expansão, que era cada vez mais crescente, por conta das necessidades sociais advindas do desenvolvimento das relações capitalistas. De outro lado, o controle das elites, mantidas ou representadas no poder, que buscavam conter a ação popular, utilizando, principalmente, mecanismos sustentados na legislação do ensino, para manter o ensino eminentemente elitista. O que se verificou a partir daí, foi o fato do ensino ter se firmado em uma proposta não sistêmica de educação, ou seja, não visando a uma proposição do ensino enquanto sistema ${ }^{5}$, uma vez que as próprias desigualdades sociais existentes resultam em "uma desigualdade sistêmica que é congênita à sociedade capitalista

50 termo sistema é utilizado no sentido de "conjunto de elementos, materiais ou não, que dependem reciprocamente uns dos outros, de maneira a formar um todo organizado" (LALANDE, 1960 apud DIAS, 1988, p. 80). Neste sentido, sistema de ensino significa "o conjunto de instituições, recursos e procedimentos, organizados de forma integrada pelo poder público, com propósito de atingir objetivos voltados para a manutenção e desenvolvimento de ensino" (CASTRO, 1998, p. 82) ainda que dentro de um movimento contraditório" (CURY, 2008, p. 1189).

A Constituição de 1946, adotando cunho democrático-liberal define no artigo 166 que a educação é "direito de todos e será dada no lar e na escola, deve inspirar-se nos princípios de liberdade e nos ideais de solidariedade humana" (BRASIL, 1946). Além da responsabilização do Estado com as questões educacionais, a família também é chamada a envolver-se com os assuntos da educação. Dentre os princípios defendidos nesta Constituição, destacam-se a obrigatoriedade e a gratuidade do ensino primário a todos nas escolas públicas. Ainda, a legislação consolida que o ensino oficial ulterior ao primário seria oferecido àqueles que provassem falta ou insuficiência de recursos (BRASIL, 1946, Art. 168, incisos II e III). Os princípios de gratuidade e obrigatoriedade do ensino público partem das concepções discutidas ainda na década de 1930 e apresentadas à sociedade e ao governo por meio do documento conhecido como Manifesto dos Pioneiros da Educação Nova.

Outros setores deveriam também envolverse com a educação, no sentido de seu financiamento e organização, como as empresas industriais, comerciais e agrícolas. Aquelas que comportassem em seus quadros de empregados mais de 100 pessoas, seriam obrigadas a manter ensino primário gratuito para os filhos de seus servidores. Além dessa normativa, ficavam as empresas industriais e comerciais obrigadas, pela imposição deste artigo, "a ministrar, em cooperação, aprendizagem aos seus trabalhadores menores, pela forma que a lei estabelecer, respeitados os direitos dos professores" (BRASIL, 1946, Art. 168, IV).

Ainda na Constituição de 1946, reafirmavase o compromisso da União em legislar sobre diretrizes e bases da educação nacional (Capítulo II, Título VI). Em seu Art. 170 aponta a incumbência da União na organização do sistema federal de ensino e também o sistema de ensino dos Territórios. O caráter do sistema federal de ensino é definido no parágrafo único deste artigo, como "supletivo, estendendo-se a todo o País nos estritos limites das deficiências locais" (BRASIL, 1946, Art. 170, Parágrafo Único). 
A organização dos Sistemas de Ensino nos Estados e no Distrito é fixada no Art. 171, sendo que para sua implementação a União "cooperará com auxílio pecuniário, o qual, em relação ao ensino primário, provirá do respectivo Fundo Nacional" (BRASIL, 1946). Essas normativas legais estabelecidas na Constituição abriam "a possibilidade da organização e instalação de um sistema nacional de educação como instrumento de democratização da educação pela via da universalização da escola básica" (SAVIANI, 1998, p. 6).

Frente a isso, Saviani (1983) propõe uma discussão sobre a existência de um Sistema Educacional no Brasil, a partir da obra Educação Brasileira: estrutura e sistema. Ao questionar a noção de sistema, sua investigação pauta-se por conflitos apresentados nos textos legais e nos discursos, afirmando que isto permite tirar algumas lições de considerável importância, pois

[...] suscitou interpretações opostas do termo 'sistema' inscrito na Constituição Federal (...). A primeira é que, desde que o problemaéabordado a partir de determinados pontos de vista político-ideológicos, a noção de 'sistema' pode receber conotações bastante diversificadas, em função das perspectivas referidas. Esta conclusão põe em foco a seguinte questão: seria possível a análise do conceito 'sistema' prescindindo de um ponto de vista político-ideológico prévio? (SAVIANI, 1983, p. 13).

Com o intuito de criar uma lei que organizasse as diretrizes e bases da educação nacional, em 1948, o Ministro da Educação Clemente Mariani encaminha o primeiro Projeto de Lei que propõe a extensão da rede escolar gratuita até o secundário e cria a equivalência dos cursos de nível médio, mediante prova de adaptação. Este anteprojeto correspondia, em seu cerne, à Constituição, alusivo aos direitos à educação. Apresentava a obrigatoriedade e gratuidade do ensino primário e gratuidade da escola pública em seus vários níveis de ensino. De igual modo, colocava as obrigações e responsabilidades do Estado relativo ao sistema de ensino, sendo que, no entanto, este projeto foi engavetado. Surge, então, em 15 de janeiro de 1959, o Projeto de Lei chamado de "Substitutivo Lacerda" que propunha, entre outros dispositivos, que a sociedade civil assumisse o controle da educação, defendendo, em vista disso, uma das formas de privatização do ensino: a educação seria financiada pelo Estado, porém vinculando a responsabilidade do financiamento estatal pelas entidades privadas, ou seja, uma forma de delegação do financiamento público aos usuários do sistema, cuja prestação de ensino caberia às instituições de cunho privado. Para isso, os grupos liberais argumentavam e alegavam a chamada "liberdade de ensino".

Ao longo de 13 anos foram travadas batalhas ideológicas com o intuito de definir-se uma lei que apontasse as diretrizes e bases para a educação nacional. Envolvimentos político-partidários, interesses de instituições privadas, divergências quanto à centralização e descentralização do ensino e mesmo reivindicações da Igreja Católica seriam parte do embate travado com setores da sociedade que se posicionavam favoráveis à intervenção pública estatal na oferta da educação nacional. Essa lei deveria substituir a Reforma Capanema de 1942, até então em vigor.

Com a discussão da primeira Lei de Diretrizes e Bases da Educação Nacional, durante o longo período que compreende de 1948 a 1961, constata-se, portanto, a disputa de duas propostas de lei que traduz a relação paradoxal e contraditória no âmbito político-econômico, cujo embate acontece entre o grupo que defendia o nacionalismo desenvolvimentista, sendo o Estado o carro-chefe no planejamento da economia estratégica para o desenvolvimento do mercado nacional, sem a dependência asfixiante do capital externo e, de outro lado, um grupo que sustentava a tese da iniciativa privada como mecanismo de gerir a economia e a educação institucionalizada, objetivando qualquer intervenção normatizadora e fiscalizadora do Estado, tanto na área econômica, como na educacional. Instaura-se o debate entre escola pública X escola privada, aos moldes dos debates entre católicos e liberais que antecederam a Constituição de 1934, sem que os interesses nacionais fossem objeto dessas discussões.

A justificativa da iniciativa privada acaba se tornando dominante na LDB e se expressa na defesa absoluta dos direitos que a família encerra referentes à escolha da educação que lhe interessa. Estas idéias vão contra a interferência e a ação do Estado, no sentido de não permitir a este a projeção 
e planificação do sistema de ensino, trazendo implícita a idéia de que esta é uma atitude totalitária. Tal ação procura defender na LDB a prerrogativa e os interesses das instituições privadas de ensino, particularmente as católicas, na obtenção do financiamento do poder público em educação.

No mencionado substitutivo do deputado Lacerda, observa-se que a discussão sobre "a liberdade de ensino", com bases inteiramente privatistas, foi o conteúdo preponderante abrangido no mesmo. Como se vê, o centro do interesse não estava no direito da família, como aparentava pautar a discussão, mas na reivindicação de recursos estatais com o intuito de beneficiar a iniciativa privada, antes mesmo que ao ensino oficial (ROMANELLI, 1984).

Para garantir e concretizar as prerrogativas absolutas da iniciativa privada, o substitutivo incumbe-se de salvaguardar a representação da mesma no Conselho Nacional de Educação e nos Conselhos Regionais, pois estes órgãos de direção de ensino seriam as instâncias responsáveis pela normatização e coordenação de recursos.

Diante das propostas apresentadas no anteprojeto, a reação foi imediata, partindo de intelectuais e educadores, que culminou, em 1959, com um grande manifesto dos educadores. Era a segunda grande campanha nacional em defesa do ensino público e gratuito. Não obstante, o texto final da primeira LDB, apresentado no Congresso em dezembro de 1961, manteve praticamente na íntegra o substitutivo Lacerda, representando certo triunfo do setor privado, garantindo-lhe o direito de ser financiado pelo Estado.

De forma muito contundente, percebe-se, principalmente no período de 1946 a 1961, um grande embate político-ideológico acirrado de um lado por educadores, intelectuais, militantes e sindicalistas, os chamados reformadores e, por outro encabeçado pela Igreja e a iniciativa privada leiga. Os privatistas entendiam a intervenção do Estado na educação como uma ação nociva, já que levava ao monopólio, comprometendo a liberdade de ensino e os princípios do ensino católico. Este posicionamento, centrado nos interesses da Igreja Católica que, diga-se de passagem, estava comprometida com as grandes forças conservadoras aristocráticas, apresentavam também a preocupação com a democratização que o país vinha passando, isto porque, durante muito tempo, a Igreja exercia exclusividade e desfrutava das benesses do Estado em relação ao ensino e não queria a perda dos privilégios políticos.

Esses debates assinalam as contradições entre os interesses públicos e privados e se refletem na Lei 4.024/61, afastando, desse modo, as concepções originariamente propostas para a Educação Pública Brasileira. Enfim, poder-se-ia afirmar, que a primeira Lei de Diretrizes e Bases da Educação Nacional nasceu ultrapassada. Mesmo com todos os debates realizados, que poderiam ter modificado substancialmente o sistema educacional brasileiro, prevalecem antigos dilemas educacionais, numa situação, agora agravada pela urgência da solução de problemas criados e aprofundados com o distanciamento que se fazia sentir entre o sistema escolar e as necessidades de desenvolvimento (ROMANELLI, 1984).

No Art. 13, define-se que "A União organizará o ensino público dos territórios e estenderá a ação federal supletiva a todo o país, nos estritos limites das deficiências locais" (BRASIL, 1961). Esta incumbência reserva o direito da União em definir políticas nacionais e de suprir necessidades de Estados e Municípios, mediante necessidades estruturais, técnicas e de financiamento do ensino.

A educação, conforme referida no Art $2^{\circ}$, é "direito de todos e será dada no lar e na escola". A LDB ainda ressalta os princípios de gratuidade e obrigatoriedade garantidos para o Ensino Primário, sem especificidade referente à faixa etária, sendo que para os demais níveis, o princípio da gratuidade fica condicionado à carência dos educandos.

Já o Art. 16 apresenta a competência dos Estados e do Distrito Federal em "autorizar o funcionamento dos estabelecimentos de ensino primário e médio não pertencentes à União, bem como reconhecê-los e inspecioná-los" (BRASIL, 1961). Observa-se nesta trajetória da LDB 4.024/61 o não reconhecimento do município como entidade federativa, o que somente vai acontecer com a Constituição Federal de 1988 e na LDB 9.394/96, com o forte apelo ao municipalismo e às ações decorrentes da participação da sociedade na definição e organização das políticas sociais. 


\section{O período de 1964 ao final dos anos 1980 - O Brasil da Ditadura à "Abertura"}

O período da ditaduramilitar nahistória brasileira foi marcado por muitas contradições. Vieira, ao salientar que "o golpe de Estado de 31 de março de 1964 decorreu de grave situação político-militar, empurrando o Presidente João Goulart para o exílio político no Uruguai" (VIEIRA, 1985, p.12-13), relata sobre os fatos que culminaram com a cassação de deputados, senadores, governadores, prefeitos e outros ocupantes da função pública e a eleição do General Castelo Branco realizada pelo Congresso Nacional em 11 de abril de 1964 para o cargo de presidente da República. Ainda, na seqüência, o autor relata:

0 Congresso Nacional deu nova direção à sociedade brasileira com 0 auxílio de várias organizações civis, nascidas e alimentadas pela classe dominante. Embora esta direção tenha utilizado militares e tecnocratas, suas origens derivam de profundos interesses nacionais e internacionais do capitalismo (VIEIRA, 1985, p.12-13).

O golpe de 1964 foi deflagrado para impedir a concretização das Reformas de Base e fez com que a idéia de democracia, que era tão sonhada, fosse enterrada de uma vez. O país mergulhou num profundo autoritarismo que durou vinte e cinco anos, tendo como características principais o desrespeito aos direitos humanos, a concentração de renda e a desnacionalização da economia.

Sobre esta situação, assim escreveu Sodré,

Aurgênciaemservirao imperialismo eparticularmente em tranqüilizá-Io quanto à capacidade de servir foi tamanha que, de imediato, praticamente, transitou uma lei de garantia de investimentos estrangeiros que só as colônias conheceram. 0 Brasil assistiu, sem demora, à tranqüila, rápida e efetiva entrega de suas riquezas naturais, à destruição sistemática de suas fontes de acumulação, ao empenho de manter o nível baixo de salários e em impedir qualquer ameaça de reivindicação salarial, à desorganização das empresas estatais a pretexto de expurgar delas os elementos ditos subversivos - que eram os que trabalhavam e acreditavam nelas - e sua substituição por apaziguados da nova situação, tão ardente nas punições e nos expurgos e nos desempregos quanto empenhados em que não subsistisse nenhuma dúvida de que a fase era de entrega mansa e pacífica de recursos naturais em benefício de multinacionais ávidas. (SODRÉ, 1984, p.61-62).
Esta foi uma fase de grande repressão na sociedade brasileira. A UNE (União Nacional dos Estudantes) foi fechada e os professores, considerados subversivos, foram demitidos, livros considerados esquerdistas foram confiscados. Segundo Basbaum:

Entre os livros que o DOPS (Delegacia de Ordem Social e Política) paulista arrola como subversivos se incluem, por exemplo, as obras mestras de Marx, Engels, Feuerbach e Plekhanov. Lá está, na lista negra da nova inquisição fancaria,o prêmio Nobel de Literatura de 1965,Mikhail Cholokov. Também contemplados Afanasiev, Draguiley, Ivostok, Zubok, Vladinov e uma vasta relação de teóricos e divulgadores da doutrina socialista, ou simples estudiosos neutros da matéria. Pelo que se depreende do material apreendido, todo livro cujo título se refira ao socialismo, marxismo ou comunismo ou tenha na capa nome de autor russo ou assemelhado deve ser recolhido à fogueira purificadora do DOPS (JORNAL DO BRASIL, 22/01/1966, apud BASBAUM, 1976, p.179).

Gohn (1995) afirma que apesar do grande controle social e político, das prisões, perseguições e torturas ocorreram muitas lutas de resistência e muitos protestos no país. A esquerda também teve grande efervescência neste período.

Motivada para resistir ao avanço das forças capitalistas no país, dado pela aliança entre os militares, o capital estrangeiro, o empresariado nacional urbano e a nova tecnocracia que começava a se formar no país, oriunda do acesso das camadas médias ao ensino universitário, as três frentes de esquerda existentes até então (PCB, PCdoB e AP) se fragmentaram em inúmeros novos grupos (GOHN, 1995, p.101).

O PCB (Partido Comunista do Brasil) dividiuse ainda mais e deu origem à Ação Libertadora Nacional coordenada por Carlos Marighela, ao PCBR (Partido Comunista Brasileiro Revolucionário) liderado por Mário Alves e ao MR8, (Movimento Revolucionário Oito de Outubro) em homenagem a Che Guevara.

A autora também destaca que a ação popular se subdividiu na fase de grande repressão à esquerda brasileira, que corresponde ao início da fase do "milagre econômico", que tem suas bases de crescimento da economia brasileira 
centradas no arrocho salarial do proletariado e na expansão do consumo das camadas médias urbanas. Com isto, pode-se perceber que a repressão desencadeada no país pelo poder militar fez calar à força os movimentos populares em defesa da democracia, da liberdade e do direito à educação. Porém, assim como as classes dominantes do país se organizaram no sentido de combater os movimentos populares, muitos líderes comunitários, educadores, estudantes, religiosos e outros componentes da sociedade civil, comprometidos com a educação e engajados na luta pela democratização, organizaram-se e realizaram muitos protestos, sendo, por isso, perseguidos, torturados, cassados e exilados

Não avaliando adequadamente a força e a velocidade com que o modelo capitalista dominante se impôs, a esquerda nacional continuava sonhando com a possibilidade de implantar um modelo que não correspondia ao curso dos acontecimentos locais. Sua estratégia baseava-se no camponês, no discurso da Reforma Agrária e na luta do campo por meio do apoio dos estudantes e "enquanto sonhava se subdividia" (GOHN, 1995, p. 101).

Durante este período, conhecido como a fase do milagre econômico, o governo deu início ao período mais absoluto de repressão, violência e supressão das liberdades civis de nossa história republicana. Desenvolveu-se um aparato de segurança com características de poder autônomo que levou aos cárceres políticos, milhares de cidadãos, transformando a tortura e 0 assassinato numa rotina. Vivia-se um período ditatorial, repressivo e, ao mesmo tempo o do "milagre" econômico; o sonho do país potência com obras faraônicas, com o (a custa do) cerceamento de liberdades democrática (GOHN, 1995, p. 101).

Sob a égide da repressão, a sociedade clama por liberdade e democracia. Este é um fator importante para os rumos da educação no processo de abertura política do início da década de 1980, preparando o país para a elaboração e consolidação da nova Lei de Diretrizes e Bases da Educação Nacional.

A gestão democrática do sistema educacional, estabelecida como princípio do ensino público na Constituição de 1988 e na LDB 9.394/96, tem sua origem, em parte, a partir dos movimentos sociais e dos embates políticos ocorridos ao final dos anos 1970 e ao longo da década de 1980. Outro fator que converge para a normatização deste princípio está calcado na descentralização políticoadministrativa do Estado Neoliberal, que marca consideravelmente o contexto de formulação destas legislações. Nesse prisma convergiam os interesses sociais e os do capital, considerando que o discurso da gestão democrática servia tanto ao processo de descentralização políticoadministrativa do Estado, como à luta da sociedade por democracia.

Ocultada a essência sob a aparência desse fenômeno, ganhava novamente o capital, pois ao descentralizar poder, colocava na sociedade a solução de seus próprios problemas, numa perspectiva privatista do Estado.

Com as novas configurações sócio-políticas, as velhas práticas antidemocráticas e ditatoriais, implantadas com o golpe de 64, tornam-se obsoletas. O novo modelo de sociedade torna indispensável a discussão em torno do papel da democracia, que agora, revisitada sob uma ótica de redemocratização, que perpassa todo o conjunto da sociedade brasileira, traz consigo uma possibilidade de ampliar a participação de toda a comunidade nos processos decisórios e organizativos desta mesma sociedade.

\section{A organização dos sistemas de ensino brasileiro e as políticas de descentralização: CF/88 e LDB 9394/96}

As atuais discussões sobre o papel do Estado cuja ação central, no modo de produção capitalista, traduz-se em conflitos que, em determinados momentos, tendem a expor fragilidades e lutas pelo poder. Segundo Werle (2005, p. 12) "as políticas do Estado são tentativas de manejar esses dilemas e lutas e, ao mesmo tempo, produzir e reproduzir acordo e compatibilidade entre a produção privada, a dependência de impostos, a necessidade de acumulação e a legitimação democrática".

Com a legitimação do capital e sua predominância sobre as necessidades humanas, configura-se a reprodução social como um 
elemento a serviço da burguesia. Nesse contexto, a democracia é entendida como

[...] a forma política mais desenvolvida de uma sociedade movida pela acumulação privada de capital, pelo individualismo burguês. Ela se caracteriza pela concepção de que todos os homens são iguais e que, portanto, as leis não devem proteger um indivíduo na sua disputa com outro [...] Contudo, ao proceder assim, a lei garante não a igualdade entre os homens, mas sim a reprodução das desigualdades. Onde todos são politicamente iguais, mas socialmente divididos entre burgueses e proletários, a igualdade política e jurídica nada mais é do que afirmação social real, das desigualdades sociais (LESSA e TONET, 2008, p. 88).

Wood (2006, p. 390) considera que no século XIX é crescente a "identificação da democracia com liberalismo", com isso observa-se mudança do foco de discussão sobre a democracia enquanto concepção que possibilita o poder popular para uma concepção que se limita à ampliação dos direitos constitucionais. Trata-se, na visão de Wood (2006), de uma disputa entre dois princípios políticos e não do resultado de uma luta de classes ou entre forças sociais - senhores versus camponeses, capital versus trabalho.

Frente a essas mudanças no conceito de democracia, fruto de novas significações e características do capitalismo, mais notadamente em relação aos aspectos capital e trabalho e pelas implicações desse modo de produção nos meios econômicos e políticos, é possível um direcionamento de olhar sobre o homem, enquanto sujeito histórico que se constitui nesse meio e que é determinado por estes mesmos contextos econômicos, políticos e culturais.

Com a redemocratização do país, consolidada na Constituição Federal de 1988, a legislação oportuniza entre outros aspectos importantes para o exercício democrático, a eleição direta dos representantes políticos, a consolidação de mecanismos que garantam a participação popular na tomada de decisões, seja através de manifestações de cunho classista, como os movimentos de trabalhadores, seja através de manifestações pela manutenção dos direitos sociais. Paralelo a este contexto de reabertura política e de reconhecimento da cidadania, a sociedade brasileira vai incorporando, por imposições de políticas mundiais de cunho neoliberais, a reforma do Estado, que se firma especialmente na década de 1990, com implicações diretas na organização do mundo da economia, do trabalho e da educação.

A organização e mobilização popular marcam o momento da discussão das temáticas educacionais quando da elaboração da Constituição Federal de 1988. Entidades, associações científicas e sindicais da área, profissionais e população envolvem-se nas discussões e apresentam propostas para a educação nacional. O movimento ocorrido no Brasil, nesta época, é fortemente marcado pelo surgimento e pela consolidação das associações e organizações de interesse popular, que no seu bojo traziam anseios oriundos dos diversos setores e grupos de profissionais, que por meio dos sindicatos e associações de classe podiam agora organizar-se na luta por causas comuns.

No que diz respeito aos processos e práticas educativas a participação e autonomia tendem a aparecer como elementos necessários para a consecução de uma proposta descentralizadora e de um novo modelo de gestão. Pensar a educação em uma concepção democrática e participativa pressupõe o envolvimento do coletivo, não somente na gestão administrativa, mas também e especialmente na gestão dos processos, de modo a favorecer aprendizagens significativas, tanto para quem ensina quanto para quem aprende.

Shiroma, destaca que:

Expressando o espírito da época, as bandeiras de luta e propostas dos educadores cobriam um amplo espectro de reivindicações a começar pelas exigências de constituição de um sistema educacional de educação orgânico - proposta recorrente desde a década de 1930. Também se firmou a concepção de educação pública e gratuita como direito público subjetivo e dever do Estado a concedê-la. Defendiase a erradicação do analfabetismo e universalização da escola pública, visando a formação de um aluno crítico (SHIROMA, 2002, 47). 
Essastransformações devemser consideradas no contexto da nova ordem econômica, a partir das implicações da globalização com definições de políticas neoliberais que objetivam o enfraquecimento dos Estados Nacionais, minimizando suas ações frente às políticas sociais, apregoando o livre mercado, a desregulação da economia, as privatizações. Tais características compõem o cenário onde serão forjadas a Constituição Federal de 1988 e posteriormente a segunda Lei de Diretrizes e Bases da Educação - LDB 9394/96.

Sarmento, assim se posiciona:

Com o enfraquecimento e a queda dos governos militares e 0 envolvimento dos diversos setores sociais na luta pela redemocratização do país, uma nova Constituição e uma nova LDB revelaram-se uma necessidade (SARMENTO, 2005, p. 1369).

Ainda que esta necessidade seja um fato, é preciso considerar que a participação popular ainda é objeto de manobras e que diversos artifícios são criados para sua limitação. As discussões sobre democratização, autonomia e qualidade da educação perpassam os discursos de intelectuais e avançam na sociedade, em especial nos setores envolvidos na defesa da escola pública. Nesse período surgem estudos que apontam a descentralização como possível saída para o insucesso das políticas anteriores. Tais estudos tinham a proposta de qualificar a educação e reconhecer igualmente o direito de cada um ao seu acesso. As políticas de descentralização são pensadas na perspectiva de eliminar burocracias, redistribuir recursos diretamente aos municípios, transpor obstáculos ou possíveis desvios, o que, ainda assim, não se traduz em autonomia, pois ocorre apenas uma redefinição de foco, com reconcentração de poder, baseado nos localismos e que objetivamente ampliam as desigualdades no Sistema de Ensino.

Machado cita que:

É óbvio que as dimensões territoriais e a diversidade do Brasil, porsisó, impõemaofertadeserviçoseducacionais descentralizados, no sentido da proximidade com 0 cidadão e com a comunidade. Entretanto, esta se dá em conformidade com o formato federativo da não- centralização, ou seja, do fortalecimento da autonomia municipal, permitindo que o município ande com as "próprias pernas", assegurando a interdependência com as demais instâncias, no cumprimento e implementação da política educacional (MACHAD0, 2002, p. 129).

Essas mudanças no âmbito educacional indicam que as definições oriundas das macropolíticas neoliberais inferem radicalmente em aspectos de organização e execução de um projeto educacional. Assim, passa-se a considerar a gestão democrática, a autonomia das instituições, os processos decisórios descentralizados com a conseqüente descentralização de ações e o repasse de um maior compromisso à sociedade e em especial à comunidade escolar, articulados com a constituição/organização dos sistemas de ensino.

Diante dos inúmeros desafios, que permeiam - mundo globalizado, com o crescente esvaziamento do Estado, a diminuição dos direitos sociais e a maior responsabilização repassada à sociedade civil, a Gestão Educacional, vista de modo mais próximo no contexto brasileiro, passa a ser percebida como possibilidade de maior participação e de integração para o desenvolvimento de um projeto sustentável para o país, que necessariamente precisa ser pensado sob o prisma educativo.

Cabe considerar que as políticas de descentralização implementadas no Brasil são definidas, em sua forma de organização, através dos sistemas educacionais: federal, estadual e municipal. Notadamente, é na esfera municipal que a responsabilidade pela articulação das ações e projetos educacionais abrange o maior contingente educacional, ou seja, parte da Educação Básica, que compreende a educação infantil e o ensino fundamental. Portanto, a observação do contexto do município, expõe a realidade na qual emergem os maiores dilemas e enfrentamentos, especialmente após a grande explosão municipalista, oportunizada pela Constituição Federal, quando o município passa a desempenhar um papel decisivo na condução de políticas sociais, dentre elas a organização da educação. 
Com a proposta de reorganização jurídica, a CF/88 propõe o chamado pacto federativo que estabelece as competências dos entes federados, em especial ampliando as responsabilidades dos Estados e dos Municípios. A ênfase na municipalização marca consideravelmente um período em que os Municípios se revestem de maior autonomia, particularmente com a descentralização das áreas fiscal e política, abarcando os demais setores: educação, saúde, assistência social e outros. Com isso, o Município, por meio de sua comunidade, acaba assumindo compromissos mesmo sem as condições necessárias para isso.

A definição de um sistema de ensino, com base nos anseios democráticos, contudo, é concebida em um modelo gestão educacional que busca aproximação com as exigências crescentes referendadas pelo modelo econômico e que se afirmam como reorganização e re-modernização do Estado. Ainda que a CF 1988, em seu art. $6^{\circ}$ preconize a educação como um dos direitos sociais e no art. 205 como um direito de todos, é possível constatarmos as enormes disparidades em todos os níveis, sejam econômicos, sociais e culturais que ampliam as diferenças e, em especial, limitam as oportunidades.

Apesar do discurso da descentralização político-administrativa não ser novo no panorama educacional brasileiro, esses interesses vão se acirrar no contexto anterior à Constituição Federal de 1988, tal como afirma Mello, evidenciando os interesses da sociedade civil por autonomia aos municípios e às escolas.

É no âmbito do município que a participação direta da população na escola básica pode acontecer de fato, desde que essa participação não seja entendida como mero sucedâneo do exercício político da cidadania no seu sentido mais pleno e mais nobre, mas, ao contrário, esteja articulada organicamente a este. Pode ser a base da construção de uma nova escola, democrática no acesso e na permanência do aluno, aberta às aspirações e valores dos seus usuários. Uma escola que sirva de fato como elo mediador entre a cultura e a realidade regionais do município e a realidade e a cultura nacionais, numa perspectiva realmente crítica tanto de uma quanto de outra (MELLO, 1986, p. 24).
Peixoto afirma que "a descentralização do ensino, processo que tem a municipalização como uma de suas formas de realização, não é uma idéia nova no Brasil" (1999, p. 101). Ainda segundo a autora, durante as décadas de 20 e 30, momentos históricos de luta pela descentralização, já eram assinalados, como o caso dos Pioneiros da Educação que apontavam a necessidade de uma ruptura com o centralismo, pois uma escola unitária não implica necessariamente em uniformidade. $\mathrm{Na}$ década de 40, com o fim do Estado Novo e nos momentos seguintes, em pleno período da ditadura militar, a descentralização foi discutida e a ela atribuía-se algumas especificidades como desburocratização, maior aproximação com os interesses locais. Contudo, somente a partir da Lei 5692/71 que vem reformular aspectos significativos da LDB 4.024/61, é que se efetiva uma política voltada à municipalização, essencialmente com a vinculação à educação dos Recursos do Fundo de Participação dos Municípios e destinação de recursos financeiros, materiais e técnicos para a manutenção da educação municipal.

A Constituição Brasileira de 1988, em seu Art. 211 refere que "a União, os Estados, o Distrito Federal e os Municípios organizarão em regime de colaboração seus sistemas de ensino" (BRASIL, 1988), explicitando a abrangência e responsabilidade de atuação de cada ente federativo na organização, oferta e atuação. Desse modo, fixa a responsabilidade da União na organização do sistema federal de ensino e também dos territórios, além da incumbência pelo financiamento das instituições de ensino públicas federais. Porém, destaca-se o $\S 1^{\circ}$ do artigo 211 da Constituição de 1988 que, dentre outras funções, atribui à União, "em matéria educacional, função redistributiva e supletiva, de forma a garantir equalização de oportunidades educacionais e padrão mínimo de qualidade do ensino mediante assistência técnica e financeira aos Estados, ao Distrito Federal e aos Municípios" (BRASIL, 1988).

A delimitação destas atribuições, diretamente relacionadas à União, objetiva a equalização das oportunidades educacionais. Esta perspectiva 
pressupõe que as disparidades regionais, a limitação financeira e técnica dos sistemas estaduais e municipais sejam consideradas, quando do planejamento das ações educacionais. Percebe-se, neste enfoque, a atenção da União na execuçãode programasqueestabelecem diretrizes e o custeio das despesas com a manutenção, estruturação do ensino, com merenda escolar, transporte escolar, programas de livros didáticos, dinheiro direto na escola e demais programas que comprovam a ação eqüitativa e supletiva da União, diretamente ligadas aos sistemas estaduais e municipais de ensino.

Ainda que as ações e programas fossem planejados de modo a atender as demandas educacionais brasileiras, Castro pondera que:

Os princípios de colaboração entre os sistemas de ensino e da ação supletiva do Poder Público Federal, reafirmados em 1988, não foram suficientes para reverter 0 quadro de pouca racionalidade nas iniciativas dos três níveis de governos em nível educacional. Mesmo após 1988, prevaleceu a prática de cada nível fazer, geralmente mal, um pouco de tudo, com frequêencia ignorando as iniciativas alheias. Apesar da evidência de ser necessário prestar maior apoio a quem dele mais precisa, a ausência de critérios técnicos e universais nas redistribuições tornou-se uma das características marcantes das ações governamentais (CASTRO, 1998, p. 84).

Esta constatação permite a reflexão sobre a atuação da União, que, com vistas a cumprir com sua função supletiva e de redistribuição de recursos, teve, desde a promulgação da lei, sua atenção voltada mais ao clientelismo e à associação às negociações político-partidárias como priorização para atender aos Municípios e Estados. Contudo, é necessário ressaltar que, recentemente, algumas ações de cunho reparador têm sido discutidas de modo a diminuir as disparidades entre os sistemas e promover a melhoria no ensino, com repasses de recursos, implementação de políticas que buscam melhorias nos índices educacionais e na qualidade do ensino ministrado no país.

\section{Breves idéias à guisa de conclusão}

A explicitação dos condicionantes históricos, com uma investigação pautada nos aspectos de organização do sistema educacional brasileiro, por si só é uma tarefa que exige maior discussão. Contudo, essa breve retomada possibilita a reflexão sobre as atuais políticas educacionais, sua implementação e origens.

Perceber o sistema educacional brasileiro e as possibilidades de participação, decorrentes da noção de descentralização, com o forte apelo ao envolvimento local na construção de sistemas educacionais próprios tornase imprescindível para que se estabeleça um diálogo sobre o papel da escola, sua necessidade e ação transformadora.

O contexto da conjuntura política e econômica internacionais, com a imposição de critérios pelo Banco Mundial, Fundo Monetário Internacional, UNESCO, ONU e outros organismos traduz-se em definições para as pautas de discussões sobre a situação das políticas educacionais brasileiras. Ao mesmo tempo, a legislação propõe, através do entendimento em torno da descentralização, a ampliação da autonomia aos Estados e Municípios, de modo que aspectos locais sejam relevantes na consecução de objetivos para o ensino. Nessa situação, ficam questionamentos sobre autonomia e participação, a partir das normativas dadas pela legislação no contexto neoliberal.

Considerando o que foi constatado tanto em relação à LDB 4024/61, quanto à LDB9394/96, questiona-se qual é a autonomia e a possibilidade de participação popular num contexto já previamente delimitado e comprometido com interesses internacionais, pautados pela lógica neoliberal e exploratória, num sistema capitalista que prioriza o lucro em detrimento dos direitos sociais e elementares da natureza humana. 


\section{Referências Bibliográficas}

BASBAUN, L. História Sincera da República. Vol. 4. São Paulo: Alfa Ômega, 1976.

BRASIL, 1946. Constituição Federal. Disponível em: http://www.planalto.gov.br/ccivil_03/Constituicao/Constituiça046.htm. Acesso em: 24 mar. 2009.

. Lei n. 4.024, de 20 de dezembro de 1961. Disponível em: http://www6.senado.gov.br/legislacao/ListaTextolntegral.action?id=75529. Acesso em: 24 mar. 2009.

Constituição da República Federativa do Brasil de 1988. Disponível em: http://www.planalto.gov.br/ccivil_03/constituicao/ constitui\%C3\%A7ao.htm. Acesso em: 24 mar. 2009.

. Lei nº 9.394, de 20 de dezembro de 1996. Disponível em: http://www.planalto.gov.br/ccivil_03/LEIS/19394.htm. Acesso em: 24 mar. 2009. CASTRO, M. L. O. A educação na Constituição de 1988 e a LDB - Lei de Diretrizes e Bases da Educação Nacional. Brasília: André Quicé, 1998.

CURY, C. R. J. Sistema nacional de educação: desafio para uma educação igualitária e federativa. Educ. Soc. [online]. vol. 29, n.105, p. 1187-1209, 2008.

DIAS, J. A. Sistema Escolar Brasileiro. In: BREJON, M. (org.). Estrutura e Funcionamento de Ensino de $1^{\circ}$ e $2^{\circ}$ Graus. São Paulo: Pioneira, 1988.

GAMBOA. S. A. S. A dialética na pesquisa em educação: elementos de contexto. In: FAZENDA, I. (org). Metodologia da pesquisa educacional. São Paulo: Cortez, 1991.

GOHN, M. G. Movimentos e Lutas Sociais na História do Brasil. São Paulo: Loyola, 1995.

LESSA, S. e TONET, I. Introdução à filosofia de Marx. $1^{\text {a }}$ ed. São Paulo: Expressão Popular, 2008.

MACHADO, M. A. M. A Gestão da Educação Básica na Perspectiva do Regime de Colaboração: algumas notas. Em Aberto, Brasília, v. 19, n. 75, p. 123-132, jul. 2002.

MELLO, G. N. É Preciso dar um Conteúdo Concreto ao Debate sobre a Municipalização do Ensino de $1^{\circ}$ Grau. Em Aberto, Brasília, ano 5, n. 29, jan./mar. 1986.

PEIXOTO, M. C. L. Descentralização da educação no Brasil: uma abordagem preliminar. In; OLIVIEIRA, D. e DUARTE, M. R. T. (Org.) Política e trabalho na escola: administração dos sistemas públicos de educação básica. Belo Horizonte: Autêntica, 1999.

RODRIGUES, M. 0 Brasil da Abertura - de 1974 à Constituinte. São Paulo: Difel, 1990.

ROMANELLI, 0. 0. História da educação no Brasil. Petrópolis: Vozes, 1984.

SARMENTO, D. C. Criação dos sistemas municipais de ensino. Educação e Sociedade, Campinas, vol. 26, n. 93, p. 1363-1390, Set./Dez. 2005.

SAVIANI, D. Educação brasileira: estrutura e sistema. - 5ª Ed. São Paulo: Saraiva, 1983.

A nova lei da educação: trajetória, limites e perspectivas. $4^{a}$ Ed. Campinas, SP: Autores Associados, 1998. (Coleção educação contemporânea).

SHIROMA, E. 0.; MORAES, M. C. M.; EVANGELISTA, 0. Pollitica Educacional. 2ª ed. Rio de Janeiro: DP\&A, 2002.

SODRÉ, N. W. História da Literatura Brasileira: seus fundamentos econômicos. 6ª Ed. Rio de Janeiro: Civilização Brasileira, 1984.

VIEIRA, E. Democracia e Política Social. São Paulo: Cortez, 1985.

WERLE, F. O. C. 0 nacional e o local: ingerência e permeabilidade na educação brasileira. Bragança Paulista: Editora Universidade São Francisco, 2005.

WOOD, E. M. Estado, democracia e globalização. In: BORON, A. A., AMADEO, J. e GONZÁLES, S. A teoria marxista hoje: problemas e perspectivas. $1^{\mathrm{a}}$ ed. $1^{\mathrm{a}}$ reimp.- Buenos Aires: Consejo Latinoamericano de Ciências Sociales - CLACSO, 2006.

Recebido em fevereiro de 2010

Aprovado em maio de 2010 